\title{
COMPORTAMENTO DO CONSUMIDOR: UM ESTUDO COMPARTATIVO DA (IN)SATISFAÇÃO ENTRE O COMÉRCIO TRADICIONAL E O SHOPPING CONQUISTA SUL
}

\section{Consumer Behavior: A Comparative Study of (In) Satisfaction Among Traditional Trade and Shopping Mall Conquista Sul}

\section{Comportamiento del consumidor: un estudio compartativo de (in) satisfacción entre el comercio tradicional y el Shopping Conquista Sur}

Carlos Fernando Faria Leite ${ }^{1}$

\footnotetext{
${ }^{1}$ Doutor pela Universidad de Barcelona-UB. Professor da Universidade do Estado da Bahia - UNEB, pesquisadorUESB admfernandoleite@gmail.com.
}

\begin{abstract}
Resumo
O objetivo deste artigo é conhecer o comportamento do consumidor e a satisfação no consumo, tendo como unidade espacial de análise o comércio tradicional e o Shopping Conquista Sul em Vitória da Conquista Bahia. O método escolhido é eclético e consistem em uma variada leitura em livros, artigos, teses e jornais. Contém um estudo quantitativo-descritivo, também qualitativo e documental. As análises foram confirmadas por testes de significância, confiabilidade e também medidas de dispersão e tendência central. Descobriu-se que os maiores índices de satisfação do consumidor foram para com o Shopping, tendo como melhores preditores de consumo: a infraestrutura física (estacionamento, segurança, climatização e entretenimento) e como pior atributo os altos preços. O Centro comercial teve como melhores preditores: Variedade de produtos e serviços, tradicionalismo, equipamentos públicos e bons preços. Já para o bairro Brasil, foram: Bairrismo, boa vizinhança, bairro de domicílio e cosmética pública favorável.
\end{abstract}

Palavras-chave: Consumo; Índices; Satisfação.

\begin{abstract}
The objective of this article is to know the behavior of the consumer and the satisfaction in the consumption, having it as a unit of analysis the traditional trade and Shopping Mall Conquista Sul in Vitória da ConquistaBahia. The chosen method is eclectic and consists of a varied reading of books, articles, theses and newspapers. It contains a quantitative-descriptive study, also qualitative and documentary. The analyzes were confirmed by tests of significance, reliability and also measures of dispersion and central tendency. It was found that the highest consumer satisfaction indexes went to Shopping Mall, with the best predictors of consumption: physical infrastructure (parking, security, air conditioning and entertainment) and one of the worst attribute of high prices. The commercial center had as its best predictors: Variety of products and services, traditionalism, public equipment and good prices. For the Brazilian neighborhood, they were: Bairrismo, good neighborhood, neighborhood of domicile and favorable public cosmetics.
\end{abstract}

Keywords: Consumption; Indexes; Satisfaction. 


\section{Resumen}

El objetivo de este artículo es conocer el comportamiento del consumidor y la satisfacción en el consumo, teniendo como unidad espacial de análisis el comercio tradicional y Shopping Conquista Sul en Vitória da Conquista-Bahia. El método elegido es ecléctico y consiste en una variada lectura en libros, artículos, tesis y periódicos. Contiene un estudio cuantitativo-descriptivo, también cualitativo y documental. Los análisis fueron confirmados por pruebas de significancia, confiabilidad y también medidas de dispersión y tendencia central. Se descubrió que los mayores índices de satisfacción del consumidor fueron para con el Shopping, teniendo como mejores predictores de consumo: la infraestructura física (aparcamiento, seguridad, climatización y entretenimiento) y como peor atributo los altos precios. El Centro comercial tuvo como mejores predictores: Variedad de productos y servicios, tradicionalismo, equipamientos públicos y buenos precios. Para el Barrio Brasil, fueron: Bairrismo, buena vecindad, barrio de domicilio y cosmética pública favorable.

Palabras clave: Consumo; Índices; Satisfacción.

\section{Introdução}

O processo de modernização do comércio tendo por base as grandes organizações varejistas está em pleno desenvolvimento. Os sistemas mais modernos de vendas, denominados de "novos formatos do varejo" a exemplo dos hipermercados, lojas de departamentos, galerias, lojas de conveniência e shopping centers estão aumentando sua participação de forma muito significativa no mercado brasileiro. No momento, devido ao grande crescimento da concorrência e competitividade, inclusive estrangeira, não basta somente uma administração eficiente, é preciso antecipar às tendências do mercado, conhecer o perfil do consumidor e satisfazê-los da melhor maneira e, se possível, superar suas expectativas a fim de ampliar o consumo e o Market share.

A empresa orientada para o mercado pretende alcançar seus objetivos ofertando produtos ou serviços que os compradores desejem consumir. Dentro deste contexto, o conceito de satisfação do cliente (seja lá pelo produto, atendimento, ambiente ou dimensão espacial) tem uma importância vital no pensamento e na prática do marketing. Assim, confirmando o descrito acima e de acordo com Kotler (1995, p.23), "satisfação é o nível de sentimento de uma pessoa, resultante da comparação do desempenho (ou resultado) de um produto em relação a suas expectativas”.

Apesar das diversas concepções desenvolvidas ao longo do tempo sobre o consumo e o comportamento do consumidor, vale dizer que muito longe ainda estão de explicar a tamanha complexidade deste importante campo do conhecimento. Contudo, o 
presente artigo (que originou de uma tese de doutorado) buscará subsídios alicerçados nas pesquisas científicas, referências bibliográficas, pesquisas secundárias e de campo a fim de contribuir para a desmistificação do assunto em questão.

A pesquisa em questão concentra-se estrategicamente na investigação de dois importantes fenômenos, relativamente interdependentes e complementares entre si, sendo o consumo e o comportamento do consumidor e tendo como o lócus da investigação a cidade de Vitória da Conquista, mais precisamente, um estudo à cerca satisfação do consumidor do mercado/comércio tradicional de Vitória da Conquista (bairros Centro e Brasil) e do Shopping Center Conquista Sul, envolvendo variáveis geográficas, econômicas, sociais e pessoais. Buscou-se contribuir para o campo do estudo que se preocupa com a problemática da geografia comercial, do marketing, do varejo, e dos novos formatos comerciais que surgiram após o processo de modernização e globalização da economia. Assim, segundo o IBGE (2015) e considerando que:

Vitória da Conquista é a terceira cidade com maior população e também terceira maior economia do estado da Bahia com 306.866 habitantes no senso de 2010 e projeção de 343.230 para 2015, perdendo apenas para a capital Salvador e Feira de Santana, portanto a segunda maior cidade do interior da Bahia;

Vitória da Conquista é a maior cidade do sudoeste Baiano, cujo estado conta com 417 municípios e uma população total de 14.016.906 habitantes no senso de 2010 e projeção de 15.203.994 para 2015 (disponível em: <http://IGBE.gov.br>. Acesso em: 12 nov. 2015);

A crescente movimenteação dos consumidores locais, assim como os consumidores advindos dos 39 municípios que constituem o sudoedeste Baiano;

A unidade de análise deste estudo é o consumidor enquanto indivíduo e que a variável dependente é o consumo e tendo em vista que o comportamento do consumidor é um dos assuntos que mais interessa aos pesquisadores da área do marketing;

Os altos índices de imigrantes e consumidores flutuantes em Vitória da Conquista, proporcionados pelos pólos da medicina avançada, ensino superior, polo de transportes e por último a implantação do Shopping Conquista Sul (o único de Vitória da Conquista e maior do Sudoeste da Bahia);

A mudanaça nos hábitos e comportamentos dos consumidores em decorrência da territorialidade e dos novos formatos comerciais que surgiram após o processo de modernização e globalização da economia, criação e construção de um shopping Center; 
$\checkmark \quad$ Considerando ainda que o comércio e os serviços são as principais atividades econômicas de Vitória da Conquista e do sudoeste baiano, cidade reconhecidamente tida como a "metrópole do sudoeste" e os maiores geradores de emprego e renda, tributos e negócios na região do sudoeste da Bahia, questiona-se uma indagação que não se cansa de calar no pesquisador: Tendo em vista oingresso dos novos formatos do varejo, quais mudanças aconteceram no consumo e no comportamento do consumidor em Vitória da Conquista? Qual o nível de satisfação dos consumidores para com as lojas do Shopping Conquista Sul e Comércio tradicional?

Assim e adjacente a este questionamento central e como questões periféricas e secundárias, o presente artigo propõe ainda atingir os seguintes objetivos específicos: Conhecer e examinar a base teórica existente em Geografia Comercial, Marketing, Economia e Sociologia no concernente ao consumo e comportamento do consumidor; Conhecer o índice de satisfação do consumidor para com o comércio varejista de Vitória da Conquista e identificar entre os espaços pesquisados, aquele de maior valor preditivo para satisfação; Conhecer a forma como os empresários percebem o comportamento e satisfação do consumidor para com o Centro comercial, o Shopping Conquista Sul e o bairro Brasil; Conhecer os melhores precedentes e os melhores atributos da satisfação do consumidor para com os três espaços estudados no concernente às variáveis socioeconômicas, espaciais e infraestruturais e, por fim, conhecer o perfil socioeconômico e pessoal dos empresários e dos consumidores do comércio tradicional e do Shopping Conquista Sul no ano de 2016.

Dito isso e, ao concluir a seção introdutória do presente artigo, o trabalho está assim estruturado: A primeira seção aborda o comportamento do consumidor; A segunda seção traz em seu bojo o assunto central deste estudo, a (in) satisfação do consumidor; A terceira aponta os caminhos adotados para investigar a verdade, através do método e desenvolvimento do estudo, que contém também a caracterização e perfil das amostras; Já a penúltima seção discute os resultados encontrados no presente estudo, e, por fim, as considerações finais.

\section{O Comportamento do Consumidor}

Depois da II Guerra Mundial, a economia americana começou a apresentar alguns traços de mudanças, e, ao invés de uma economia centrada nos ofertantes, mudou para um foco nos consumidores, o último elo da cadeia. Devido à economia de escala e novos modelos eficazes na gestão de materiais, a extraordinária capacidade de 
produção tinha gerado um excedente, começando assim a gerar estoques e, consequentemente, encalhamento de mercadorias e dificuldade de escoamento (PINTO; LARA, 2007).

Assim, vários autores começaram a focar esforços no entendimento de como o consumidor deveria ser conquistado para fazer frente à grande concorrência. No concernente ao campo de conhecimento estabelecido na ciência comportamental, havia também uma crescente realização de um considerável corpo de conhecimento oriundo das ciências behavioristas - aborígine da teoria das relações humanas - com raízes na psicologia cognitiva, antropologia e do próprio behaviorismo na década de 50 , entre outros, - que poderia ser útil para funções de negócios, especialmente no que envolvesse o consumo, consumidor e de maneira mais ampla, o marketing e a geografia comercial, passando assim, a contribuir para os estudos do comportamento do consumidor: desejos, afetividades, emoções e impulsos.

Pesquisadores e profissionais de marketing têm testemunhado uma mudança de paradigma que, essencialmente, enfatiza a manutenção dos consumidores, pela busca por relacionamentos mais permanentes e estáveis (como a lealdade e fidelização dos consumidores à marca, produto, empresa e serviço) que gerem ganhos na lucratividade individualmente (ENGEL et al., 2002). Ganhar a confiança e manter o consumidor satisfeito e rentável ${ }^{2}$ frente a produtos e serviços se torna uma das atividades mais importantes da área de marketing. Concomitantemente, o estudo das emoções, tanto na psicologia como no marketing, tem sido examinado por uma variedade de perspectivas e interpretada de diversas maneiras.

Foxall (1999) partiu de uma análise funcional em que o comportamento do consumidor é o centro nas pesquisas envolvendo as empresas e o consumo. A finalidade da empresa se resumiria em criar e reter clientes servindo-lhes com vantagem sobre as demais empresas em um contexto competitivo de mercado. A partir do comportamento do consumidor, então, uma empresa surge, se estabelece e dele depende sua longevidade. O movimento é iniciado quando o consumidor passasse diante a loja e concluído com a entrada nesta, entendendo que na fase que antecede a compra, entrar na loja é uma etapa necessária. Ele foi baseado na perspectiva comportamental para investigar comportamentos de aproximação a lojas. O fluxograma da figura 1 ilustra a ideia de Foxall (1999):

\footnotetext{
${ }^{2}$ Segundo pesquisas amplamente divulgadas e de domínio público, se conquistar um novo cliente chega a ser cinco vezes mais oneroso que manter um já existente, devido a custo com propaganda, publicidade, promoções e o próprio risco de inadimplência.
} 
Figura 1- Trajetória dos Consumidores pelo mercado.

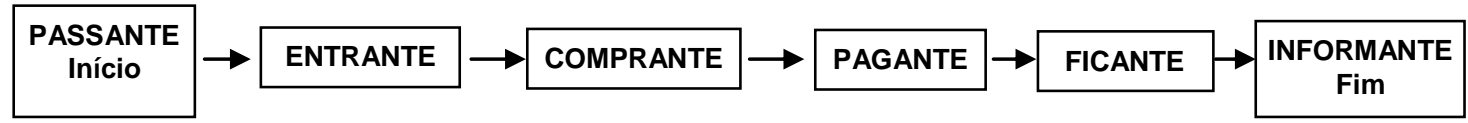

Fonte: adaptado de foxall pelo autor (2016)

Entender o que o consumidor quer ou precisa é desafiador embora possa parecer que não. É preciso considerar o universo de variáveis que afetam uma decisão de consumo, a quantidade de decisões envolvidas e sobrepostas e como estas se influenciam mutuamente (FOXALL, 2006).

O surgimento do conceito de marketing, na década de 1950, evoluiu para expressar o reconhecimento da importância do consumidor no processo de compras e assinalou a necessidade de se estudar, concomitantemente, o comportamento do consumidor, sendo então definido por Arnold, Price e Zinkhan (2004, p. 9) como “o processo de indivíduos ou grupos adquirindo, usando e se desfazendo de produtos, serviços, ideias ou experiências".

No que concerne aos antecedentes do comportamento do consumidor, Solomon (2002) comenta a respeito do modelo de Triandis, que sugere não apenas as intenções seriam antecessores do comportamento, mas outras variáveis, como hábito ou algum episódio ligado ao passado, por exemplo. Solomon (2002, p. 177) afirma: “[...] não é de surpreender, então, que em alguns momentos o comportamento de compra passado tenha sido considerado como um fator de previsão melhor do comportamento futuro".

Para Solomon (2002) a pressuposição básica de que o comportamento é intencional pode ser inválida em uma variedade de casos, incluindo atos impulsivos, súbitas mudanças na situação da pessoa, busca de novidade, ou mesmo, a simples compra repetida. Honkanen; Olsen; Verplanken (2005, p. 99 apud Lacerda 2007, p. 11) confirma tal pressuposto e acrescenta que, “[...] de fato, o comportamento passado frequentemente aparece como a mais forte das variáveis preditoras".

Existe o conceito unidimensional proposto por Fishbein; Ajzen (1975), que destaca a quantidade de afeto que uma pessoa sente por um objeto, sendo que as crenças (cognição) e intenções (comportamento desejado) são vistas como relacionadas à atitude e que impactam diretamente no comportamento de compra. 
Figura 2 - Visão contemporânea das relações entre crenças, sentimentos, atitude, intenção comportamental e comportamento.

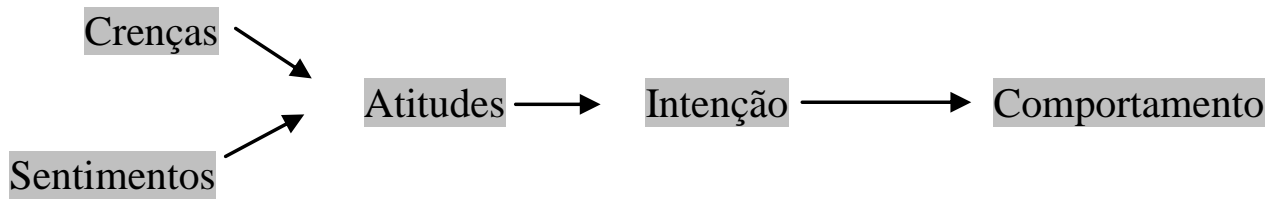

Fonte: Engel, Blackwell e Miniard (2000).

Assim, Fishbein; Ajzen (1975, p. 216) definem outra variável relevante para o estudo do comportamento do consumidor que é a atitude, sendo conceituada como "sentimento positivo ou negativo de um indivíduo com relação a um determinado objeto de comportamento". Os consumidores têm atitudes em relação a uma ampla gama de objetos: desde comportamentos muito específicos relacionados a produtos ou serviços (como comprar um creme dental, sabonete, xampu de uma marca e não de outra) até comportamentos mais gerais relativos ao consumo (como a decisão sobre comprar em loja do mercado tradicional, shopping Center ou através de comércio eletrônico).

Face destas considerações preliminares a respeito do comportamento do consumidor, como sendo "pano de fundo" para o entendimento da satisfação, apresentase a seguir a segunda seção teórica e terceira seção deste estudo, denominada de (in) satisfação do consumidor, cerne deste estudo,

\section{(In) Satisfação do Consumidor, aspectos teorico-metodologicos.}

Atualmente é lugar comum reconhecer que satisfazer as necessidades do consumidor - assim como entender o consumo - é um dos principais objetivos das organizações, O reconhecimento deste princípio básico de gestão vem tornando cada vez mais importante o monitoramento da satisfação do consumidor como forma de avaliar o seu desempenho global, quer visem o lucro ou não. Como ressaltam diversos estudos, em um mundo onde a concorrência é grande e onde o consumidor é mais informado e exigente e a avaliação constante da satisfação ${ }^{3}$ traz excelentes benefícios, como forma de realimentar e controlar o esforço de uma empresa sob o ponto de vista do mercado e dos seus clientes.

\footnotetext{
3 Sob o ponto de vista de um órgão regulador, a avaliação da satisfação do consumidor tem sua importância destacada pela possibilidade de incluir no processo de acompanhamento das empresas, além de indicadores técnicos de desempenho, também indicadores da avaliação do consumidor quanto ao consumo de bens e serviços. Este assunto será tratado no tópico pertinente sobre regulação.
} 
Existem na literatura dois tipos de definições que diferem em função da ênfase que dão à satisfação do consumidor quer como resultado quer como processo. Algumas definições conceptualizam a Satisfação do Consumidor - SC como resultado de uma experiência de consumo. Neste sentido, a satisfação do consumidor é definida como "a resposta do consumidor a uma avaliação da discrepância percebida entre as expectativas (ou outro tipo de norma da performance) e a performance corrente de um produto [ou serviço, grifo nosso] percebida após o seu consumo" (KOTLER, 1995).

Esta abordagem centrada na orientação para o processo (process-oriented), comparada com a abordagem orientada para o resultado (outcome-oriented), traz uma visão ampliada da SC, na medida em que a concebe na perspectiva da experiência de consumo como um todo. Ela chama mais a atenção para perspectivas de processos perceptuais, avaliativos e psicológicos como geradores da SC (YI, 1991). Já Oliver (1981, 1997), sugere que a satisfação pode ser melhor entendida como uma avaliação da surpresa inerente à aquisição de um produto e/ou à experiência de consumo, uma comparação antes e depois do consumo.

Já a dissonância cognitiva é citada por Engel; Oliver (1995) referindo-se ao processo e o resultado emocional final da verificação da diferença entre o que se desejou e o que ocorreu. Para Engel et al (1995, p.19) a satisfação é "uma avaliação pós-consumo em que a alternativa escolhida, no mínimo, alcance ou mesmo exceda as expectativas". Segundo Möwen (1995) a satisfação do consumidor é “a atitude geral sobre um produto ou serviço posterior a sua aquisição e uso. É o julgamento de avaliação pós-compra resultante de uma compra específica”. Na visão de Oliver (1996, p.23) a satisfação é uma "reação completa do consumidor ao ato de consumir". Assim, a satisfação do consumidor em consumir produtos ou serviços em lojas do centro da cidade ou mesmo em shopping centers, de acordo com Oliver (1981, p.36), pode ser analisada em três estágios:

$1^{\circ}$ Estágio - $\mathrm{O}$ consumidor cria uma expectativa em relação à loja em si, ou seja, em relação aos fatores de serviço que irá receber (composto por estacionamento, produto, segurança, preço, bem estar etc.);

$2^{\circ}$ Estágio - Acontece a formação da satisfação em relação ao processo de consumo (experiência de consumo), relativo aos produtos e serviços obtidos, influenciada também pela satisfação relativa à experiência de compra.

$3^{\circ}$ Estágio - É formada uma avaliação global da satisfação, relativa ao processo de suporte dado pela loja (mix do ambiente organizacional) e ao consumo dos produtos em si. Consequentemente e face ao exposto, a satisfação global é uma associação da satisfação em relação à 
experiência de compra e da satisfação em relação à experiência de consumo dos produtos adquiridos.

Johnson, Anderson e Fornell (1995) ressaltam que a satisfação é considerada cumulativa quando "trata-se de uma experiência total de consumo com um determinado produto ou serviço". O estudo da satisfação, na opinião de Oliver (1996, p.23), é visto sob quatro perspectivas:

1) Considera a satisfação como sendo uma busca individual, um objetivo a ser atingido através do consumo de produtos e serviços;

2) Apresenta o ponto de vista da empresa. Em uma sociedade capitalista grande parte das empresas buscam o lucro e quase sempre sua rentabilidade é resultante da venda repetida de seus produtos ou serviços ao longo do tempo. Por conseguinte, se os clientes de uma dada empresa não ficarem satisfeitos e interromperem o consumo de seus produtos e/ou serviços, ou substituírem o fornecedor, possivelmente o seu lucro será afetado, mais cedo ou mais tarde; 3 ) Mostra o mercado como um todo, aonde cada vez mais a satisfação - e também a insatisfação - dos consumidores vêm sendo examinadas no sentido de exercer influência na regulamentação das políticas regentes no mercado, tanto no setor público quanto no setor privado e 4) A perspectiva da sociedade é a mais ampla e trata da satisfação do indivíduo não só como um agente de consumo, mas como um cidadão em relação à sua saúde física, mental e financeira.

Oliver (1996) considera que a mensuração da satisfação do consumidor através da análise do desempenho do produto ou serviço tem suas vantagens (mediante o diagnóstico, avaliar as causasłatributos e os níveis de (in) satisfação e desvantagens (análise de desempenho não explicar o porquê de determinado atributo ser um problema ou um benefício para o consumidor).

A lealdade do consumidor é um importante elemento que possibilita a mensuração da relação cliente-empresa, permitindo o aumento dos lucros e a retenção de consumidores. Já o custo de mudança ${ }^{4}$ representa qualquer fator que torne mais difícil ou dispendioso para o cliente trocar de fornecedor (JONES; MOTHERSBAUGH; BEATTY, 2000 apud MATOS; ROSA, 1999).

Neste sentido, pode ser um cliente atacadista, varejista ou mesmo o cliente final, visto que conquistar um novo cliente se torna muito dispendioso para o ofertante, comparada à sua retenção. Já do ponto de vista do consumidor, algumas "vantagens" adquirida pela fidelização, a exemplo da barganha por melhores preços e maiores prazos, se esvaem com o rompimento desta relação.

\footnotetext{
${ }^{4}$ Assunto de grande relevância para os estudos em comportamento do consumidor, que não será tratado neste artigo por limitações do número de páginas.
} 
Entre as variáveis estudadas e analisadas aqui, uma delas são as relações causais (GIL, 1999). O estudo deve ser considerado correlacional e comparativo, uma vez que estabelece correlações entre as diversas variáveis sob estudo, também entre as lojas que compõem o comércio tradicional versus o Shopping Conquista Sul.

Gil (1999) afirma que o presente estudo pode ser caracterizado como pesquisa empírica, que pode, adicionalmente, também ser denominada como "pesquisa prática", pelo fato de trabalhar o comportamento de indivíduos em um espaço geográficoque tem por objetivo aprofundar a descrição de uma determinada realidade ou fenômeno, implicando em um exame intensivo a qualquer nível da realidade social, que fornece uma compreensão complexa e ampla dos fenômenos, haja vista a consideração do aspecto subjetivo de uma ação social.

No concernente à pesquisa quali-quantitativa, ela investigará a verdade via questionário misto, contendo questões fechadas e abertas a respeito do perfil e comportamento do consumidor e empresários, assim como os índices de satisfação do consumidor dentre outros e, de forma congruente com as perspectivas hegemônicas no estudo neste domínio, pois partilham uma estratégia metodológica comum: usam largamente estudos de cortes transversais ${ }^{5}$, com a utilização de dados quantitativos e sofisticadas análises estatísticas. Neste sentido, foram utilizadas escalas tipo Likert para mensurar os diversos construtos envolvidos nos modelos teóricos submetidos a testes estatísticos e recorrem à análise quantitativa.

A metodologia utilizada também foi à discussão indireta a partir de fontes bibliográficas. Assim, segundo Antônio Carlos Gil (2002) a pesquisa bibliográfica é desenvolvida com base em material já elaborado, constituído, principalmente, de livros e artigos científicos. A sua principal vantagem reside no fato de permitir ao investigador fazer a cobertura de uma gama de fenômenos muito mais ampla do que aquela que poderia pesquisar diretamente. Esta vantagem se torna particularmente importante quando o problema de pesquisa requer dados muito dispersos no espaço, sendo também indispensável nos estudos históricos, visto que, em muitas situações, não há outra maneira de conhecer os fatos passados senão com base em dados bibliográficos e/ou através da pesquisa secundária.

\footnotetext{
${ }^{5}$ Em um dado momento da pesquisa, propicia uma descrição instantânea da freqüência de certos atributos dos indivíduos integrantes da população definida.
} 
A unidade de análise deste estudo - população alvo ${ }^{6}$ - constitui-se de: 1) Empresários que possuem lojas no Shopping, comércio do Centro da cidade, do bairro Brasil e demais bairros e 2) consumidores residentes em Vitória da Conquista, capital do estado e, por fim, consumidores potenciais e/ou flutuantes da microrregião do Sudoeste da Bahia. O período da pesquisa entre consumidores e empresários aconteceu entre os dias 01 de junho a 30 de julho de 2016, ou seja, foram disponibilizados dois meses para a devolução dos instrumentos respondidos, quer seja os questionários impressos ou mesmo via e-mail e redes sociais.

Tabela 1 - Plano de amostragem aplicado entre os lojistas afiliados ao CDL e o Shopping Conquista Sul.

\begin{tabular}{l|l|l}
\hline Tipo/Local & $\begin{array}{l}\text { Quantitativo das Lojas do Shopping } \\
\text { Conquista Sul e associadas à Câmara de } \\
\text { Diretores Lojistas - CDL }\end{array}$ & Percentual \\
\hline 1. População & $599:[409$ (CDL) +190 (Shopping) $]$ & $100 \%$ \\
\hline 2.Questionários Entregues & 599 & $100 \%$ \\
\hline 3. Amostra obtida (devolutiva) & 35 & $5,8 \%$ \\
\hline
\end{tabular}

Fonte: Pesquisa de Campo, 2016.

Quanto à pesquisa entre os consumidores, o cálculo para determinação do tamanho da amostra se deu através de procedimentos estatísticos apropriados, utilizando-se para tanto, a fórmula para população finita de Stevenson (1981, p. 45): N $=\mathrm{t}^{2} x \mathrm{~s}^{2} x \mathrm{~N} / \mathrm{s}^{2} x \sigma^{2}+\mathrm{e}^{2}(\mathrm{~N}-1)$

Assim, utilizando a população conquistense como o universo para os intervalos de classe para idade entre 20 a 84 anos (pelo senso de 2010 totalizam 200.181 pessoas, sendo 94.482 homens e 105.699 mulheres) na fórmula acima, obteve via cálculo da amostra para margem de erro de 5\% um quantitativo de 399 questionários como amostra para ouvir os consumidores.

Tabela 2 - Dados comparativos entre população e amostra da pesquisa: questionários entregues/aplicados e recebidos entre os consumidores.

\begin{tabular}{l|l|l}
\hline \multicolumn{1}{c|}{ Tipo/Local } & Quantidade & Percentual \\
\hline 1. População & 200.181 & $100 \%$ \\
\hline 2. Questionários aplicados & 1.000 & $0,5 \%$ \\
\hline 3.Relação da amostra obtida/ população & 227 & $0,11 \%$ \\
\hline $\begin{array}{l}\text { 4.Relação da amostra obtida } \\
\text { /questionários aplicados }\end{array}$ & 227 & $22,7 \%$ \\
\hline
\end{tabular}

Fonte: Pesquisa de Campo, 2016.

Para conhecer os índices de satisfação do consumidor foi escolhido o modelo da multiplicidade de indicadores da satisfação $^{8}$ proposto por Oliver e Desarbo (1988) e

\footnotetext{
${ }^{6}$ População é um conjunto de indivíduos ou objetos que apresentam pelo menos uma característica em comum (GIL, 1996, p. 11).

${ }^{7}$ Dos 190 espaços/lojas do Shopping, apenas 145 estavam ocupados na ocasião da pesquisa
} 
Oliver e Swan (1989), visto que trabalha uma gama mais ampla de construtos que a dos demais paradigmas, inclusive o da desconformidade que se baseia nos resultados de pesquisas anteriores que avaliaram as influências da resposta afetiva sobre a satisfação. Neste modelo, cada item é indicador de um construto formador da satisfação com peso semelhante. O pressuposto é de que haja uni dimensionalidade neste grupo, o que garantiria a mensuração do construto. Assim, o Escore Global de Satisfação (ESG) pode ser obtido pela soma simples dos escores indicados em cada um dos itens da escala. Estes modelos se prestam principalmente à avaliação global da satisfação do consumidor e/ou utilizando as medidas de tendência central como média moda e mediana e também medidas de dispersão, para assim confirmar os resultados, que, por sua vez, oferecerão uma visão mais ampla dosindicadores. Além disso, este indicador oferece outra vantagem que é a separação e o conhecimento dos construtos da Satisfação e seus melhores antecedentes e consequentes, visto ser estes alguns objetivos do presente estudo (MARCHETTI; PRADO, 1998).

A fim de implementar os procedimentos de análise estatística, (cálculo de frequência das variáveis e fórmulas estatísticas, a exemplo das medidas de tendência central - média, moda, mediana - e de dispersão - desvio padrão, variância), utilizou-se o pacote estatístico SPSS (Statistical Package for the Social Sciences) ${ }^{9}$ versão 20.0 subprograma Frequencies e Statistics para Windows.

Quanto à validação das escalas e índices de confiabilidade, para Churchill (1979), o processo de validação pode ser entendido como um conjunto de procedimentos estatísticos, cujo objetivo fundamental é produzir escores observados o mais próximo possível dos escores verdadeiros da realidade pesquisada e a fidedignidade é definida como a capacidade de apresentar, ao longo do tempo e uso, medidas consistentes nas pesquisas. Neste sentido, considerando que a pesquisa foi analisada com base nos dois instrumentos tornou-se necessário conhecer a confiabilidade das escalas, a fim de obter resultados com margens confiáveis. O índice de confiabilidade das medidas proposta no presente estudo é medido com base no Alpha de Cronbach, que foi ser obtido no programa SPSS. Considerando que o Alpha de cronbach ideal, segundo a literatura pertinente, varia entre 0,70 - 0,90, Além dele, foi utilizado também o "Qi-Quadrado” obtido no mesmo programa SPSS.

\footnotetext{
${ }^{8}$ Os outros dois modelos analisados foram: modelos baseados em Métodos de Equações Estruturais e o Paradigma da Desconformidade

${ }^{9}$ Pacote estatístico para as ciências sociais.
} 
Tabela 3 - Caracterização e perfil da amostra obtida na pesquisa entre os consumidores: variáveis pessoais, profissionais e espaciais. ${ }^{10}$

\begin{tabular}{|c|c|c|c|c|}
\hline $\begin{array}{l}\text { VARIÁVEL } \\
\text { INDEPENDENTE }\end{array}$ & $\begin{array}{l}\text { Dados } \\
\text { absolutos - } \\
\text { (n) }\end{array}$ & \begin{tabular}{|l|} 
Dados relativos da \\
amostra \\
(Percentual) \\
\end{tabular} & $\begin{array}{l}\text { Significância } \\
\text { combinada }\end{array}$ & $\begin{array}{l}\text { Significância } \\
\text { linear }\end{array}$ \\
\hline IDADE & 227 & $100 \%$ & & \\
\hline Até 20 anos & 5 & 2,2 & & \\
\hline De 21 a 30 anos & 64 & 28,2 & $\mathrm{~F}=1,347$ & $\mathrm{~F}=5,511$ \\
\hline De 31 a 40 anos & 86 & 37,9 & $\mathrm{SIG}=0,245$ & $\mathrm{SIG}=0,20$ \\
\hline De 41 a 50 anos & 35 & 15,4 & & \\
\hline De 51 a 60 anos & 26 & 11,5 & & \\
\hline Acima de 60 anos & 11 & 4,8 & & \\
\hline SEXO & 227 & $100 \%$ & & \\
\hline Masculino & 107 & 47,1 & $\mathrm{~F}=3,083$ & - \\
\hline Feminino & 120 & 52,9 & $\mathrm{SIG}=0,80$ & - \\
\hline CIDADE ONDE RESIDE & 227 & $100 \%$ & & \\
\hline Vitória da Conquista & 199 & 87,7 & & \\
\hline Guanambi & 12 & 5,3 & $\mathrm{~F}=2,169$ & $\mathrm{~F}=0,617$ \\
\hline Itapetinga & 3 & 1,3 & SIG $=0,073$ & SIG $=0,433$ \\
\hline Salvador (Capital do Estado) & 3 & 1,3 & & \\
\hline Outras Cidades $^{11}$ & 10 & 4,4 & & \\
\hline ESTADO CIVIL & 227 & $100 \%$ & & \\
\hline Solteiro & 122 & 53,7 & & \\
\hline Casado & 89 & 39,2 & $\mathrm{~F}=2,567$ & $\mathbf{F}=\mathbf{0 , 0 0 0}$ \\
\hline $\begin{array}{l}\text { Outros (Divorciado, Viúva e } \\
\text { Separado). }\end{array}$ & 16 & 7 & SIG $=0,079$ & SIG $=0,987$ \\
\hline ESCOLARIDADE & 227 & $100 \%$ & & \\
\hline Ensino fundamental & 2 & 0,9 & & \\
\hline Ensino Médio & 28 & 12,3 & & \\
\hline Superior Incompleto & 38 & 16,7 & $\mathrm{~F}=0,699$ & - \\
\hline Superior Completo & 66 & 29,1 & $\mathrm{SIG}=0,594$ & - \\
\hline Pós-Graduado & 93 & 41 & & \\
\hline BAIRRO RESIDÊNCIA & 227 & $100 \%$ & & \\
\hline Boa Vista & 20 & 8,8 & & \\
\hline Alto Maron & 7 & 3,1 & & \\
\hline Bairro Brasil & 23 & 10,1 & & \\
\hline Candeias & 62 & 27,3 & $\mathrm{~F}=0,716$ & $F=0,05$ \\
\hline Centro da Cidade & 21 & 9,3 & SIG $=0,735$ & SIG $=0,941$ \\
\hline Felícia & 5 & 2,2 & & \\
\hline Ibirapuera & 7 & 3,1 & & \\
\hline Iracema & 2 & 0,9 & & \\
\hline Patagônia & 8 & 3,5 & & \\
\hline Recreio & 18 & 7,9 & $\mathrm{~F}=0,716$ & $\mathrm{~F}=0,05$ \\
\hline Urbis (II, III, IV e V.Serrana) & 10 & 4,4 & SIG $=0,735$ & SIG $=0,941$ \\
\hline Outros Bairros $^{12}$ & 29 & 12,8 & & \\
\hline Não Reside em V. Conquista & 15 & 6,6 & & \\
\hline RENDA & 227 & $100 \%$ & & \\
\hline Até 1 Salário Mínimo & 22 & 9,7 & & \\
\hline De 1 a 3 S.M. & 75 & 33 & $\mathrm{~F}=0,453$ & $\mathrm{~F}=1,225$ \\
\hline De 3 a 5 S.M. & 54 & 23,8 & SIG $=0,770$ & SIG $=0,270$ \\
\hline
\end{tabular}

10 O percentual está aproximado de acordo às normas de estatística: Somente até decimais os valores destacados pela Moda (valores que mais se repetem).

${ }^{11}$ Caculé, Jânio Quadros, Candiba, Goiania, Itarantim, Jequié, Montes Claros, Teixeira de Freitas e Tremedal.

${ }^{12}$ Os outros Bairros que compõem esta tabela 47.736 são: Morada dos Pássaros, Cidade Maravilhosa, Cruzeiro, Espírito Santo, Guarani, Inocoop II, Jatobá, Sumaré, Zabelê, Panorama, Petrópolis, Primavera e São Vicente. 


\begin{tabular}{l|l|l|l|l}
\hline $\begin{array}{l}\text { VARIÁVEL } \\
\text { INDEPENDENTE }\end{array}$ & $\begin{array}{l}\text { Dados } \\
\text { absolutos - } \\
\text { (n) }\end{array}$ & $\begin{array}{l}\text { Dados relativos da } \\
\text { amostra } \\
\text { (Percentual) }\end{array}$ & $\begin{array}{l}\text { Significância } \\
\text { combinada }\end{array}$ & $\begin{array}{l}\text { Significância } \\
\text { linear }\end{array}$ \\
\hline De 5 a 15 S.M. & 62 & 27,3 & & \\
\hline Acima de 15 S.M. & 14 & 6,2 & & \\
\hline
\end{tabular}

Fonte: Pesquisa de Campo, 2016.

Em se tratando que a tabela é autoexplicativa e que há limites de páginas para o referido artigo, o pesquisador entendeu que se torna desnecessário e redundante tecer interpretações ou mesmo apresentar os gráficos quanto às tabelas 3 e 4 que descrevem o perfil dos consumidores e empresários. Entretanto, os maiores achados deste grupo de dezoito questões inerentes à satisfação do consumidor com os três espaços geográficos, comparando a média de satisfação com as variáveis independentes pessoais e espaciais, ou seja, as que apresentaram maiores coeficientes de significância foram: estado civil com $F=2,567$ e significância de 0,079 na significância combinada e de $F=0,000$ na significância linear. A outra variável foi bairro de residência com $F=0,05$ e significância=0,941. Isso quer dizer que estas foram as variáveis de maior valor preditivo encontrado nesta escala, sugerindo uma congruência entre satisfação do consumidor entre os espaços pesquisados com os bairros de residência e também estado civil, se caracterizando neste trabalho como os melhores preditores de satisfação.

A satisfação do consumidor nos três espaços estudados (Shopping, bairro Brasil e Centro Comercial) e entre os dois grupos pesquisados (consumidores e empresários). Apresenta, conforme dito anteriormente, o modelo de mensuração da satisfação do Consumidor adotado no presente estudo foi o modelo da multiplicidade de Indicadores da satisfação proposto por Oliver (1981).

Assim, o que interessa de fato ao pesquisador e para o presente estudo é como o consumidor avalia os três espaços. Quanto ao empresário é uma percepção dele enquanto consumidor e de como ele imagina que seja a satisfação dos consumidores. Os resultados assim como a análise serão apresentados na tabela 4, em percentual:

Tabela 4 - A satisfação do consumidor percebida pelos empresários e consumidores - em percentual.

\begin{tabular}{l|c|c|c|c|c|c|c}
\hline Questões & $\begin{array}{c}\text { Centro } \\
\text { Comercial } \\
(\boldsymbol{\%})\end{array}$ & $\begin{array}{c}\text { Bairro } \\
\text { Brasil } \\
(\boldsymbol{\%})\end{array}$ & $\begin{array}{c}\text { Shopping } \\
\text { Conquista } \\
\text { Sul (\%) }\end{array}$ & $\begin{array}{c}\text { Todos } \\
\text { Eles(\%) }\end{array}$ & $\begin{array}{c}\text { Nenhum } \\
\text { Deles (\%) }\end{array}$ & $\begin{array}{c}\text { Não Se } \\
\text { aplica (\%) })\end{array}$ & $\begin{array}{c}\text { TOTAL } \\
(\%)\end{array}$ \\
\hline $\begin{array}{l}\text { Empresários } \\
\begin{array}{l}\text { Atendimento } \\
\text { vendedores e atendentes } \\
\text { nos três espaços. }\end{array}\end{array}$ & $\mathbf{2 9}$ & $\mathbf{9}$ & $\mathbf{1 7}$ & $\mathbf{3 4}$ & $\mathbf{1 1}$ & $\mathbf{0}$ & $\mathbf{1 0 0 \%}$ \\
$\begin{array}{l}\text { Consumidores } \\
\text { Empresários- }\end{array}$ & $\mathbf{2 4}$ & $\mathbf{5}$ & $\mathbf{2 7}$ & $\mathbf{2 8}$ & $\mathbf{1 0}$ & $\mathbf{7}$ & $\mathbf{1 0 0 \%}$ \\
\hline
\end{tabular}




\begin{tabular}{|c|c|c|c|c|c|c|c|}
\hline Questões & $\begin{array}{c}\text { Centro } \\
\text { Comercial } \\
(\%)\end{array}$ & $\begin{array}{c}\text { Bairro } \\
\text { Brasil } \\
(\%)\end{array}$ & \begin{tabular}{|c|} 
Shopping \\
Conquista \\
Sul $(\%)$
\end{tabular} & $\begin{array}{c}\text { Todos } \\
\operatorname{Eles}(\%)\end{array}$ & $\begin{array}{l}\text { Nenhum } \\
\text { Deles }(\%)\end{array}$ & $\begin{array}{c}\text { Não Se } \\
\text { aplica }(\%)\end{array}$ & $\begin{array}{c}\text { TOTAL } \\
(\%)\end{array}$ \\
\hline \multicolumn{8}{|c|}{\begin{tabular}{ll|l} 
Ambiente & interno & \\
agradável & &
\end{tabular}} \\
\hline Consumidores & 4 & 2 & 76 & 8 & 3 & 8 & $100 \%$ \\
\hline $\begin{array}{l}\text { Empresários- } \\
\text { Mudei meus hábitos de } \\
\text { consumo após conhecer } \\
\text { este lugar }\end{array}$ & 17 & 3 & 46 & 3 & 20 & 11 & $100 \%$ \\
\hline Consumidores & 10 & 4 & 23 & 8 & 44 & 12 & $100 \%$ \\
\hline $\begin{array}{l}\text { Empresários- } \\
\text { Vêm aqui porque encontro } \\
\text { de tudo o que preciso } \\
\text { inclusive serviços diversos }\end{array}$ & 49 & 6 & 23 & 20 & 3 & $\mathbf{0}$ & $100 \%$ \\
\hline Consumidores & 40 & 5 & 31 & 11 & 7 & 6 & $100 \%$ \\
\hline $\begin{array}{l}\text { Empresários- } \\
\text { Este ambiente me traz } \\
\text { status }\end{array}$ & $\mathbf{0}$ & $\mathbf{0}$ & 57 & 3 & 26 & 14 & $100 \%$ \\
\hline Consumidores & 3 & 1 & 26 & 5 & 54 & 11 & $100 \%$ \\
\hline $\begin{array}{l}\text { Empresários- } \\
\text { Os dias e horários de } \\
\text { funcionamento deste lugar } \\
\text { me agradam muito }\end{array}$ & $\mathbf{0}$ & 6 & 74 & 14 & 3 & 3 & $100 \%$ \\
\hline Consumidores & 6 & 1 & 76 & 8 & 2 & 7 & $100 \%$ \\
\hline $\begin{array}{l}\text { Empresários- } \\
\text { As lojas deste lugar } \\
\text { possuem } \\
\text { climatização e iluminação } \\
\text { ideais para mim }\end{array}$ & 6 & $\mathbf{0}$ & 69 & 11 & 6 & 9 & $100 \%$ \\
\hline Consumidores & 2 & 3 & 70 & 11 & 8 & 7 & $100 \%$ \\
\hline $\begin{array}{l}\text { Empresários- } \\
\text { Este ambiente possui os } \\
\text { melhores preços }\end{array}$ & 60 & 11 & 3 & 14 & 3 & 9 & $100 \%$ \\
\hline Consumidores & 44 & 16 & 7 & 8 & 16 & 8 & $100 \%$ \\
\hline $\begin{array}{l}\text { Empresários- } \\
\text { Prefiro este espaço devido } \\
\text { às promoções oferecidas } \\
\text { pelas lojas }\end{array}$ & 40 & 3 & 11 & 26 & 6 & 14 & $100 \%$ \\
\hline Consumidores & 45 & 7 & 15 & 10 & 14 & 9 & $100 \%$ \\
\hline $\begin{array}{l}\text { Empresários- } \\
\text { Este ambiente é seguro } \\
\text { contra assaltos e roubos }\end{array}$ & 0 & 0 & 91 & 0 & 9 & 0 & $100 \%$ \\
\hline Consumidores & 3 & 3 & 64 & 4 & 17 & 9 & $100 \%$ \\
\hline $\begin{array}{l}\text { Empresários- } \\
\text { Os banheiros deste espaço } \\
\text { (ou das lojas) são limpos e } \\
\text { agradáveis. Valorizo isso }\end{array}$ & 3 & 0 & 69 & 0 & 0 & 11 & $100 \%$ \\
\hline Consumidores & 3 & 2 & 72 & 8 & 5 & 9 & $100 \%$ \\
\hline $\begin{array}{l}\text { Empresários-Gosto do } \\
\text { estacionamento (público } \\
\text { ou privado) deste espaço: } \\
\text { sempre encontro vagas e } \\
\text { não perco tempo }\end{array}$ & 6 & 0 & 80 & 0 & 14 & 0 & $100 \%$ \\
\hline Consumidores & 4 & 4 & 64 & 7 & 11 & 10 & $100 \%$ \\
\hline $\begin{array}{l}\text { Empresários- } \\
\text { O ambiente interno da loja } \\
\text { é bonito e requintado: }\end{array}$ & 6 & 0 & 66 & 11 & 9 & 9 & $100 \%$ \\
\hline
\end{tabular}




\begin{tabular}{|c|c|c|c|c|c|c|c|}
\hline Questões & \begin{tabular}{|c|} 
Centro \\
Comercial \\
$(\%)$
\end{tabular} & $\begin{array}{c}\text { Bairro } \\
\text { Brasil } \\
(\%) \\
\end{array}$ & \begin{tabular}{|c|} 
Shopping \\
Conquista \\
Sul (\%) \\
\end{tabular} & $\begin{array}{c}\text { Todos } \\
\text { Eles }(\%)\end{array}$ & $\begin{array}{c}\text { Nenhum } \\
\text { Deles }(\%)\end{array}$ & $\begin{array}{c}\text { Não Se } \\
\text { aplica }(\%)\end{array}$ & $\begin{array}{c}\text { TOTAL } \\
(\%)\end{array}$ \\
\hline \multicolumn{8}{|l|}{ gosto de lugares assim } \\
\hline Consumidores & 9 & 3 & 63 & 14 & 3 & 9 & $100 \%$ \\
\hline $\begin{array}{l}\text { Empresários- } \\
\text { O ambiente é bem } \\
\text { adaptado e seguro para } \\
\text { deficientes físicos }\end{array}$ & $\mathbf{0}$ & $\mathbf{0}$ & 77 & 6 & 9 & 9 & $100 \%$ \\
\hline Consumidores & 2 & 4 & 60 & 8 & 17 & 9 & $100 \%$ \\
\hline $\begin{array}{l}\text { Empresários - } \\
\text { Julgo que os meus valores } \\
\text { são compatíveis com os } \\
\text { lugares onde consumo. } \\
\text { Aqui me identifico e } \\
\text { realizo. }\end{array}$ & 23 & 11 & 29 & 14 & 6 & 17 & $100 \%$ \\
\hline Consumidores & 22 & 6 & 12 & 28 & 25 & 8 & $100 \%$ \\
\hline $\begin{array}{l}\text { Empresários- } \\
\text { Gosto de consumir neste } \\
\text { local porque encontro } \\
\text { constantemente com meus } \\
\text { amigos. }\end{array}$ & 9 & 6 & 46 & 14 & 6 & 20 & $100 \%$ \\
\hline Consumidores & 16 & 5 & 25 & 21 & 24 & 10 & $100 \%$ \\
\hline $\begin{array}{l}\text { Empresários- } \\
\text { A mídia (propaganda em } \\
\text { rádio, tv, internet e outras) } \\
\text { interfere muito no } \\
\text { consumo. Motivo este que } \\
\text { frequento este ambiente }\end{array}$ & 17 & 3 & 17 & 29 & 14 & 20 & $100 \%$ \\
\hline Consumidores & 14 & 5 & 15 & 15 & 41 & 10 & $100 \%$ \\
\hline \begin{tabular}{lr}
\multicolumn{2}{l}{ Empresários- } \\
No geral, \\
necessidades \\
consumidor \\
PLENAMENTE \\
ATENDIDAS neste lugar.
\end{tabular} & 17 & $\mathbf{0}$ & 40 & 14 & 14 & 14 & $100 \%$ \\
\hline Consumidores & 25 & 6 & 22 & 23 & 17 & 8 & $100 \%$ \\
\hline
\end{tabular}

Fonte: Pesquisa de Campo, 2016.

Conforme se observa na tabela 5 , embora constem as três medidas de tendência central (moda, média aritmética e mediana) e também as duas medidas de dispersão (desvio padrão e variância) serão consideradas para fins de análise, apenas a moda e o desvio padrão, por serem mais pertinentes e eficazes para este tipo de pesquisa quantitativa a que nos propomos. As demais medidas serão analisadas de forma secundária para confirmar ou refutar os achados da moda e desvio padrão.

Dito isso, os resultados confirmam que, conforme tabelas e análises apresentadas logo abaixo, os consumidores tem uma satisfação maior com o Shopping Conquista Sul, assim como os empresários também assim o sentem e percebem o mundo do consumo e consumidores. Sandall; Oliveira-Castro Neto (2007, p.6) confirmam esta tendência através da seguinte frase: “Os shoppings centers vêm sendo" descritos como, cada vez 
mais, o habitat principal dos consumidores, desde a década de noventa, quando então estes formatos se multiplicaram por todo o mundo, começando pelas metrópoles dos países desenvolvidos, para então gradativamente irem alcançando o interior e as cidades médias. A tabela 5, apresenta as medidas de tendência central e dispersão quanto aos ítens de satisfação:

Tabela 5 - Comparativo entre as medidas de tendência central e dispersão sob a perspectiva dos consumidores versus empresários.

\begin{tabular}{|c|c|c|c|c|c|}
\hline QUESTÕES & MÉDIA & MEDIANA & MODA & $\begin{array}{l}\text { DESVIO } \\
\text { PADRÃOO }\end{array}$ & VARIÂNCIA \\
\hline $\begin{array}{l}\text { Empresários - atendimento dos } \\
\text { vendedores e atendentes nos três } \\
\text { espaços. }\end{array}$ & 2,9 & 3 & 4 & 1,442 & 2,081 \\
\hline Consumidores & 3,1 & 3 & 4 & 1,501 & 2,254 \\
\hline 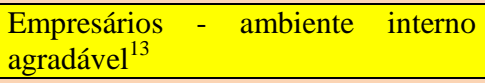 & 3,2 & 3 & 3 & 0,677 & 0,459 \\
\hline Consumidores & 3,2 & 3 & 3 & 0,991 & 0,982 \\
\hline $\begin{array}{l}\text { Empresários - mudei meus hábitos } \\
\text { de consumo após conhecer este lugar }\end{array}$ & 3,4 & 3 & 3 & 1,576 & 2,482 \\
\hline Consumidores & 4,0 & 5 & 5 & 1,478 & 2,186 \\
\hline $\begin{array}{l}\text { Empresários - venho aqui porque } \\
\text { encontro de tudo o que preciso } \\
\text { inclusive serviços diversos }\end{array}$ & 2,2 & 2 & 1 & 1,330 & 1,770 \\
\hline Consumidores & 2,6 & 3 & 1 & 1,562 & 2,438 \\
\hline $\begin{array}{l}\text { Empresários - este ambiente me traz } \\
\text { status }\end{array}$ & 4,0 & 3 & 3 & 1,200 & 1,440 \\
\hline Consumidores & 4,4 & 5 & 5 & 1,168 & 1,364 \\
\hline $\begin{array}{l}\text { Empresários - os dias e horários de } \\
\text { funcionamento deste lugar me } \\
\text { agradam muito }\end{array}$ & 3,2 & 3 & 3 & 0,731 & 0,534 \\
\hline Consumidores & 3,2 & 3 & 3 & 1,005 & 1,009 \\
\hline $\begin{array}{l}\text { Empresários - as lojas deste lugar } \\
\text { possuem uma climatização e } \\
\text { iluminação ideais para mim }\end{array}$ & 3,4 & 3 & 3 & 1,114 & 1,240 \\
\hline Consumidores & 3,4 & 3 & 3 & 0,986 & 0,973 \\
\hline $\begin{array}{l}\text { Empresários - Este ambiente possui } \\
\text { os melhores preços }\end{array}$ & 2,1 & 1 & 1 & 1,700 & 2,891 \\
\hline Consumidores & 2,6 & 2 & 1 & 1,805 & 3,257 \\
\hline $\begin{array}{l}\text { Empresários - prefiro este espaço } \\
\text { devido às promoções oferecidas } \\
\text { pelas lojas }\end{array}$ & 2,9 & 3 & 1 & 1,871 & 3,499 \\
\hline Consumidores & 2,6 & 2 & 1 & 1,8 & 3,241 \\
\hline
\end{tabular}

\footnotetext{
${ }^{13}$ Ambiente Interno Agradável - por unanimidade - todas as medidas de tendência central, ou seja, média aritmética (3,2 para os dois grupos), mediana (3) e moda (3) indicam que o Shopping Conquista Sul apresenta o maior índice de satisfação para este questionamento com $76 \%$ dos respondentes, ou seja, mais de 2/3 da amostra se posicionou mais satisfeito com o Shopping em relação à agradabilidade do espaço. Este atributo da escala se apresenta como um excelente preditor de satisfação em favor do novo formato do varejo, podendo ser comprovado pelo pequeno desvio padrão em relação á média $(0,677$ por parte dos empresários e 0,991 por parte dos consumidores). Coincidentemente, todas as medidas foram iguais entre o grupo dos consumidores e empresários.
} 


\begin{tabular}{|c|c|c|c|c|c|}
\hline QUESTÕES & MÉDIA & MEDIANA & MODA & $\begin{array}{l}\text { DESVIO } \\
\text { PADRÃO }\end{array}$ & VARIÂNCIA \\
\hline $\begin{array}{l}\text { Empresários - este ambiente é seguro } \\
\text { contra assaltos e roubos }\end{array}$ & 3,1 & 3 & 3 & 0,568 & 0,323 \\
\hline Consumidores & 3,5 & 3 & 3 & 1,179 & 1,39 \\
\hline $\begin{array}{l}\text { Empresários - os banheiros deste } \\
\text { espaço (ou das lojas) são limpos e } \\
\text { agradáveis. valorizo isso }\end{array}$ & 3,5 & 3 & 3 & 1,146 & 1,314 \\
\hline Consumidores & 3,4 & 3 & 3 & 1,058 & 1,12 \\
\hline $\begin{array}{l}\text { Empresários - gosto do } \\
\text { estacionamento (público ou privado) } \\
\text { deste espaço: sempre encontro vagas } \\
\text { e não perco tempo }\end{array}$ & 3,17 & 3 & 3 & 0,891 & 0,793 \\
\hline Consumidores & 3,48 & 3 & 3 & 1,176 & 1,383 \\
\hline $\begin{array}{l}\text { Empresários - o ambiente interno da } \\
\text { loja é bonito e requintado: gosto de } \\
\text { lugares assim }\end{array}$ & 3,43 & 3 & 3 & 1,145 & 1,311 \\
\hline Consumidores & 3,27 & 3 & 3 & 1,184 & 1,403 \\
\hline $\begin{array}{l}\text { Empresários - o ambiente é bem } \\
\text { adaptado e seguro para deficientes } \\
\text { físicos }\end{array}$ & 3,49 & 3 & 3 & 0,981 & 0,963 \\
\hline Consumidores & 3,6 & 3 & 3 & 1,153 & 1,33 \\
\hline $\begin{array}{l}\text { Empresários - julgo que os meus } \\
\text { valores são compatíveis com os } \\
\text { lugares onde consumo. Aqui me } \\
\text { identifico e realizo. }\end{array}$ & 3,20 & 3 & 3 & 1,729 & 2,988 \\
\hline Consumidores & 3,52 & 4 & 4 & 1,625 & 2,64 \\
\hline $\begin{array}{l}\text { Empresários - gosto de consumir } \\
\text { neste local porque encontro } \\
\text { constantemente com meus amigos. }\end{array}$ & 3,63 & 3 & 3 & 1,497 & 2,240 \\
\hline Consumidores & 3,62 & 4 & 3 & 1,542 & 2,378 \\
\hline $\begin{array}{l}\text { Empresários - a mídia (propaganda } \\
\text { em rádio, tv, internet e outras) } \\
\text { interfere muito no consumo. Motivo } \\
\text { este que frequento este ambiente }\end{array}$ & 3,8 & 4 & 4 & 1,677 & 2,812 \\
\hline Consumidores & 3,92 & 5 & 5 & 1,558 & 2,427 \\
\hline $\begin{array}{l}\text { Empresários - no geral, minhas } \\
\text { necessidades de consumidor são } \\
\text { PLENAMENTE ATENDIDAS neste } \\
\text { lugar. }\end{array}$ & 3,51 & 3 & 3 & 1,579 & 2,492 \\
\hline Consumidores & 3,23 & 3 & 1 & 1,614 & 2,605 \\
\hline $\begin{array}{l}\text { MÉDIA GERAL DE SATISFAÇÃO } \\
\text { EMPRESÁRIOS }\end{array}$ & 3,22 & 3,176 & 2,5 & 0,650 & 0,423 \\
\hline $\begin{array}{l}\text { MÉDIA GERAL DE SATISFAÇÃO } \\
\text { CONSUMIDOREES }\end{array}$ & 3,4265 & 3,381 & 3,29 & 0,82341 & 0,678 \\
\hline
\end{tabular}

Fonte: Pesquisa de Campo, 2016.

Considerando que o Alpha de cronbach ideal, segundo a literatura pertinente, varia entre 0,70 - 0,90 foram analisadas os dezoito itens que compõem a escala de satisfação proposta por Oliver e Desarbo (1988) e Oliver e Swan (1989) para com os três espaços do consumo, sendo dois do mercado tradicional (bairro Brasil e Centro 
Comercial) e outro localizado no bairro Felícia, o Shopping Conquista Sul. Assim, as questões inerentes à satisfação do consumidor respondidas pelos consumidores nestes três espaços geográficos apresenta um índice ótimo de confiabilidade, com um alpha de 0,833 para o estudo das variáveis satisfação (18/227). Já a mesma escala respondida pelos empresários, apresentou um valor ainda mais confiável, com alpha de 0,743, vindo o pesquisador a afirmar que tais achados são significativamente importantes para afirmar que: O Shopping Conquista Sul de Vitória da Conquista é o espaço com maiores índices de satisfação, sendo preferido por nove entre os dezoito itens pesquisados entre os consumidores. Já o centro comercial, teve a preferência em três itens e os demais foi para todos eles, nenhum e não se aplica. Para a avaliação dos empresários, o shopping teve a preferência em treze itens, enquanto que os cinco restantes foram para todos eles, nenhum deles e não se aplica. Assim, considerando apenas os três espaços, o shopping obteve $75 \%$ das preferências dos consumidores, enquanto o Centro Comercial obteve $25 \%$ e o bairro Brasil $0 \%$.

Quanto à média geral de satisfação entre os empresários de todos os atributos desta escala e fazendo um estudo de todas as questões referentes à maneira como os empresários enxergam a satisfação do consumidor, com scores de 0,650 para desvio padrão e 0,423 para variância, portanto altamente significativos, conclui que o shopping apresenta os maiores scores de satisfação (sob a perspectiva dos empresários) com escores de: 2,5 (moda) 3,22 para a média; 3,17 para a mediana. Assim, o Shopping aparece como espaço de maior satisfação entre os três pesquisados.

Já no que diz respeito à média geral de satisfação percebida pelos consumidores, os escores são muito parecidos, o que demonstra uma boa percepção de como os empresários "enxergam" os consumidores. Os escores foram: 3,29 para a moda (próximo do shopping); 3,38 para mediana e 3,42 para a média aritmética, confirmando os valores centrais compatíveis com o novo modelo do varejo, o shopping Center.

Quanto aos empresários, no geral, foram perspicazes em perceber empiricamente as tendências, sentimentos e satisfações/insatisfações dos consumidores para com os três espaços estudados, ou seja, Shopping Conquista Sul, Centro Comercial e bairro Brasil uma vez que além de conhecerem e perceberem o comportamento dos consumidores, também consome no mercado. Na maioria quase que absoluta dos casos, as respostas foram compatíveis entre aquelas dadas pelos consumidores e aquelas apontadas pelos empresários que, "se colocaram na posição de consumidor" para avaliar os questionamentos. Assim, extraindo-se a tirando-se a média geral de todos os atributos desta escala e fazendo um estudo de todas as questões referentes à maneira como os 
empresários enxergam a satisfação do consumidor, com escores de 0,650 para desvio padrão e 0,423 para variância, portanto altamente significativos, conclui que o shopping também apresenta os maiores scores de satisfação (sob a perspectiva dos empresários) com escores de: 2,5 (moda) 3,22 para a média; 3,17 para a mediana. Assim, o shopping também aparece como espaço de maior satisfação entre os três pesquisados.

Outra certeza latente e confirmada pelos respondentes é que o bairro Brasil é o espaço de menor satisfação entre os três pesquisados, apresentando quase na totalidade dos atributos, um quantitativo muito pequeno de consumidores que o avaliam positivamente, conforme se pode comprovar pelos percentuais, pelas medidas de tendência central (moda, mediana e média aritmética) e também pelas medidas de dispersão.

\section{Considerações Finais}

Procurou-se com a presente investigação conhecer as mudanças no comportamento do consumidor nos últimos anos bem como a (in)satisfação dos consumidores, tendo como unidade espacial de análise o comércio tradicional de Vitória da Conquista (no Centro comercial e bairro Brasil) e Shopping Conquista Sul, correlacionado o consumo com as variáveis geográficas e socioeconômicas.

Descobriu-se com a investigação, que este novo formato do varejo (o shopping) representou impactos significativos na economia local e regional e também culminou em novos hábitos de consumo por parte dos conquistenses, criando novas maneiras de consumo na população, criando também uma identidade com alguns padrões internacionais de consumo, a exemplo da americanização, consumo de franquias, restaurantes fast food e tantos outros hábitos de consumo e convivência com os formatos ditos "tradicionais e modernos".

De uma maneira geral e quanto ao objetivo que pretendeu conhecer o índice de satisfação do consumidor (ISC) para com o comércio varejista de Vitória da Conquista, os escores apontaram predição dos consumidores pelo novo formado do varejo, o Shopping, sendo mais bem avaliados nos grupos de consumidores e empresários tanto no concernente às expectativas quanto na satisfação comprovada após apreciação. Dito isso, o "ambiente de shoppings centers é o mais satisfatório para se consumir se comparado aos demais formatos", uma vez que todos os índices e medidas utilizadas foram compatíveis com este resultado. Os atributos da escala que continha dezoito itens 
com maiores valores preditivos foram compatíveis para: ambiente interno agradável e requintado, horários de funcionamento, climatização e iluminação, segurança, estacionamento e banheiros adaptável para deficiente físico.

O centro comercial foi o segundo espaço mais bem avaliado, cujos atributos de maior predileção foram: diversidade de produtos e serviços e possuir os melhores preços. Adicionalmente a isto, acrescenta-se a tradição e o fato de existir os equipamentos públicos e privados neste espaço.

O bairro Brasil, apresenta nesta ordem: bairrismo e boa vizinhança; comodidade e praticidade para como os residentes daquele bairro, praticidade no consumo e localização estratégica graças às rodovias que cortam o território e avenidas e passeios largos. Assim, tais características mapeadas são compatíveis também com as respostas objetivas apresentadas pelos consumidores.

A pesquisa comprovou também que, entre os dois grupos de respondentes pesquisados (consumidores e empresários), o bairro Brasil é o espaço de menor satisfação entre eles, não apresentando em nenhum dos atributos da escala, um escore superior aos outros dois, sendo muito pequeno o quantitativo de consumidores que o avaliam positivamente, conforme se pode comprovar pelas medidas pertinentes. Entretanto, com base nas informações secundárias do IBGE, SEI e outros órgãos, o bairro Brasil se configura como o segundo maior comércio de V. da Conquista, sendo este o motivo de o pesquisador ter comparado o mesmo na pesquisa.

Quanto ao questionamento de que os consumidores vão ao shopping - em sua maioria - para entretenimento e lazer, cerca de $90 \%$ concordam com este item, o que nos legitima dizer que este novo formato do varejo pensou em agregar valor ao consumo de produtos através dos serviços como cinema, praça de alimentação, parques, brinquedoteca, consumo do varejo, assim como proporcionar outros benefícios que o comércio de rua não o faz, a exemplo de comodidade, estacionamento fechado gratuito, cobertura, segurança, climatização, luminosidade artificial, dentre outros.

Em relação aos custos com os pontos nas lojas de rua, os shoppings centers apresentam os mais custos operacionais (soma do aluguel, do condomínio e do fundo de promoção) se comparado aos outros espaços. Neste sentido, a pesquisa apontou entre os três grupos pesquisados que os custos operacionaisdo shopping são altíssimos, sendo este o pior atributo do ponto comercial o que, inevitavelmente, o lojista terá que repassar para os consumidores, sendo encarado por eles, como preços finais bem mais elevados. 
Quanto aos limites do trabalho, os resultados apresentados neste estudo, apesar de indicarem bons índices de confiabilidade, se deparam com uma incógnita que persegue as pesquisas quantitativas de corte transversal que é o fato de visto que as respostas intencionalmente demonstradas nos instrumentos podem não corresponder ao real sentimento do entrevistado, podendo vir a camuflar a realidade, mesmo que cumpra a função de assegurar para o próprio indivíduo a consistência entre o dizer e o fazer.

Vale destacar, contudo, que os dados aqui apresentados constituem explorações iniciais, fornecendo pistas a serem perseguidas em estudos cujos delineamentos possibilitem acompanhar as mudanças no mundo do consumo, priorizando as variáveis espaciais, visto que neste trabalho foram melhores valorizadas as questões socioeconômicas, enfraquecendo de certa forma o trabalho.

Dentre as várias recomendações apresentadas para uma agenda de pesquisa que tenha por objetivo superar os problemas ora enfrentados, encontra-se a necessidade de estudar múltiplos estágios entre o consumo e o regionalismo, a fim de incentivar estudos exploratórios e qualitativos com enfoque mais qualitativo, desenvolver estudos longitudinais e vincular a pesquisa a outras áreas de investigação. Recomenda-se, também, outras iniciativas de pesquisas acadêmicas com o foco no consumo coletivo, ficando aqui a sugestão para que possa complementar a presente tese e viabilizar o estudo do consumo em múltiplas nuances, transcendendo os países e também continentes, $\mathrm{o}$ individual e também o coletivo.

A discussão aqui levantada ainda carece, certamente, de um amadurecimento teórico e de um acúmulo de conhecimentos a respeito de experiências práticas que possam, por sua vez, enriquecer o trabalho. Nosso esforço será totalmente recompensado se outros pesquisadores europeus e brasileiros se sentirem desafiados a aprofundar as questões aqui levantadas ou mesmo a substituí-las por outras mais pertinentes. Se lograrmos êxito esse intento, teremos somado alguma contribuição à busca de uma reflexão sobre o consumo e o comportamento do consumidor assim como os desafios encontrados pelos pesquisadores para equacionar os problemas nesta instigante, porém desafiadora missão de entender os indivíduos e a satisfação destes com o consumo e os espaços geográficos.

\section{Referências}


AJZEN, Icek, FISHBEIN, Martin. Understanding attitudes and predicting social behavior. New Jersey: Prentice Hall; 2000.

ENGEL, J. F.; KOLLAT, D. T.; BLACKWELL, R. D. The Influence of Social Stratification on Consumer Behaviour Social Class. In Consumer Behaviour. New York, 1968, p.263-308, 1968.

FISHBEIN, Martin; AJZEN, Icek. Understanding attitudes and predicting social behavior. New Jersey: Prentice Hall; 1975.

FOXALL, Gordon R. The Psychological Basis of Marketing. In: Marketing Theory A Student Text, London: Thomson Learning, 2006, p. 86-101.

GIL, Antônio Carlos. Como Elaborar Projetos de Pesquisa. 3.ed. São Paulo: Atlas, 1999.

IBGE. Instituto Brasileiro de Geografia e Estatística. Atlas do Censo Demográfico 2010. Rio de Janeiro: IBGE, 2015.

JOHNSON, M.; ANDERSON, E.; FORNELL, C. Rational and Adaptative Performance Expectations in a Customer Satisfaction Framework. Journal of Consumer Research, v. 21, p. 695-707, march 1995.

KOTLER, Philip. Administração de Marketing. 10. ed. São Paulo: Prentice Hall, 2000 .

Administração de Marketing: Análise, Planejamento, Implementação e

Controle. São Paulo: Atlas, 1995.

LACERDA, Tales Sarmento. Teorias da Ação e o Comportamento do Consumidor: Alternativas e Contribuições aos Modelos de Fishbein e Ajzen. Anais do $31^{\circ}$ ENANPAD - Encontro Nacional dos Programas de Pós-Graduação em Administração, Rio de Janeiro, set. 2007.

OLIVER, R. L. A cognitive model of the antecedents and consequences of satisfaction decisions. Journal of Marketing Research. v. 17, p. 460-469, 1980.

Measurement and Evaluation of Satisfaction Processes in Retailing Settings. Journal of Retailing, v. 57, n. 3, 1981, p. 25-48. Journal of Retailing, v. 80, n. 3, 1997, p15-29.

Cognitive, affective, and attribute bases of the satisfaction response.

Journal of Consumer Research, v. 20, p. 418-430, 1993.

PINTO, Marcelo de Rezende; LARA, José Edson. A Pesquisa na Área do Comportamento do Consumidor: Uma Análise da Produção Acadêmica Brasileira Entre 1997 e 2006. Anais do 31ํNANPAD - Encontro Nacional dos Programas de PósGraduação em Administração, Rio de Janeiro, set.2007.16p.

SANDALL, Hugo Leonardo Póvoa; OLIVEIRA-CASTRO, Jorge Mendes de Neto. Aproximação de Lojas em um Shopping Center: Análise do Comportamento do Consumidor e a Influência de Diferenciação de Marca e Localização sobre Taxas de 
Conversão: Anais do $31^{\circ}$ ENANPAD - Encontro Nacional dos Programas de PósGraduação em Administração, Rio de Janeiro, set.2007. 16p.

SOLOMON, M.R. O Comportamento do Consumidor. Porto Alegre: Bookman, 2002.

STEVENSON, William J. Estatística Aplicada à Administração. Trad. Alfredo Alves de Farias. São Paulo: Ed. Harper e Row do Brasil, 1981.

YI, S., FABER, R. Impulse buying: its relations to personality traits and cues. Advances in Consumer Research, v. 27, p. 179-186, 1981.

Recebido em: 22/10/2017

Aceito para publicação em: 30/11/2017 